\title{
Prevalence of osteoporosis and osteopenia in elderly patients scheduled for total knee arthroplasty
}

\author{
Maximilian M. Delsmann ${ }^{1,2} \cdot$ Constantin Schmidt ${ }^{1,2} \cdot$ Moritz Mühlenfeld $^{1} \cdot$ Nico Maximilian Jandl $^{1}$. \\ Christoph Kolja Boese ${ }^{1} \cdot$ Frank Timo Beil $^{1} \cdot$ Tim Rolvien $^{1}{ }^{10} \cdot$ Christian Ries $^{1}$
}

Received: 2 October 2021 / Accepted: 30 November 2021 / Published online: 17 December 2021

(c) The Author(s) 2021

\begin{abstract}
Introduction Osteoporosis is a common comorbidity in elderly patients with osteoarthritis (OA) and may increase perioperative complications in orthopedic surgery (e.g., component migration, periprosthetic fractures). As there is no investigation of bone mineral density (BMD) in elderly patients prior to total knee arthroplasty (TKA) in Europe, we investigated this issue with a particular focus on a potential treatment gap.

Materials and methods We assessed the BMD by dual-energy X-ray absorptiometry (DXA) in 109 consecutive elderly patients (age $\geq 70$ years) scheduled for TKA. In addition to a detailed assessment of osteoporosis and osteopenia, the influence of clinical risk factors and radiological OA severity on BMD was evaluated using group comparisons and linear regression models. In addition, we analyzed differences in BMD between patients scheduled for TKA vs. total hip arthroplasty (THA). Results Of the included 109 patients, 19 patients (17.4\%) were diagnosed with osteoporosis and 50 (45.9\%) with osteopenia. In the osteoporotic patients, a clinically relevant underdiagnosis concomitant with a serious treatment gap was observed in $95.0 \%$ of the patients. Body mass index, OA grade, and glucocorticoid use were identified as independent factors associated with BMD. No differences in BMD were found between the patients scheduled for TKA vs. THA.

Conclusions Considering the high prevalence of osteoporosis and osteopenia in elderly patients, DXA screening should be recommended for patients $\geq 70$ years indicated for TKA.
\end{abstract}

Keywords Osteoporosis · Total knee arthroplasty $\cdot$ Osteoarthritis $\cdot$ Bone mineral density $\cdot$ DXA

\section{Introduction}

Total knee arthroplasty (TKA) represents a successful surgical procedure for treating patients with end-stage osteoarthritis (OA) of the knee for whom nonoperative treatment has been unsuccessful [1]. Several novel technologies have

Maximilian M. Delsmann and Constantin Schmidt contributed equally to this work.

Tim Rolvien

t.rolvien@uke.de

Christian Ries

c.ries@uke.de

1 Department of Trauma and Orthopaedic Surgery, Division of Orthopaedics, University Medical Center HamburgEppendorf, Martinistraße 52, 20246 Hamburg, Germany

2 Department of Osteology and Biomechanics, University Medical Center Hamburg-Eppendorf, Lottestraße 59, 22529 Hamburg, Germany been recently proposed to optimize the outcome of this procedure [2-4]. Knee OA is a highly prevalent joint disorder with an increasing occurrence within the last century $[5,6]$ that seems to be attributable not only to aging and obesity, but also to multifactorial influences of the modern environment $[5,7]$. Therefore, a closer investigation of this disease and the affected elderly patient population is needed to further decipher the influence of medical conditions and comorbidities on onset and outcome, respectively.

Owing to the considerable risk of osteoporosis in elderly patients with OA [8-10], the International Society for Clinical Densitometry (ISCD) recommends an assessment of bone mineral density (BMD) in women aged $\geq 65$ years and men aged $\geq 70$ years prior to orthopedic surgery, including TKA, to avoid adverse outcomes [11]. In TKA, poor bone status has been associated with intraoperative and periprosthetic fractures, migration of components, and aseptic loosening [12-16]. Furthermore, decreased BMD in the proximal tibia has been identified as a risk factor for 
migration of the tibial component [16]. In this context, a circumferential cortical bone support of the proximal tibial component appears mandatory to prevent implant migration. Nonetheless, BMD assessment prior to TKA plays a minor role in a clinical setting so far and is often not performed on a routine basis.

A significant prevalence of osteoporosis in patients undergoing arthroplasty has been reported previously, but methodological differences, such as a broad age range, pre- vs. postoperative evaluation, no differentiation between knee vs. hip replacement were limiting factors, resulting in a heterogeneous osteoporosis frequency ranging from 20.0 to $59.8 \%$ $[8,9,17-20]$. In addition, there appears to be a geographic difference in the prevalence of osteoporosis before total joint arthroplasty, with more than twice as high values in Asian than in more western countries [8, 9, 17-19]. Importantly, no study exists investigating the occurrence of osteoporosis in an elderly population prior to TKA in Europe. In this study, we aimed to analyze for the first time BMD measured by dual-energy X-ray absorptiometry (DXA) in a consecutive series of elderly OA patients aged $\geq 70$ years (i.e., unbiased approach) in a Central European country before TKA, focusing on a possible treatment gap.

\section{Methods}

\section{Study cohort}

We retrospectively analyzed 109 consecutive patients aged $\geq 70$ years who underwent TKA due to end-stage OA in our department in 2018 and 2019. Two patients who initially presented to our department were excluded due to cancer with skeletal metastases $(n=1)$ and inoperability due to severe disease $(n=1)$. Demographic parameters (age, sex, BMI) and relevant clinical risk factors for osteoporosis and increased fracture risk (previous fractures, rheumatoid arthritis, oral glucocorticoid intake for longer than three months in the past or at present, regular consumption of more than three units of alcohol per day, tobacco use, diabetes mellitus) were obtained in all patients. Furthermore, as part of routine clinical workup, BMD was determined preoperatively before TKA by DXA according to the ISCD recommendation [11]. For patients with an indication for osteoporosis treatment, bone-specific drugs were recommended or initiated according to the osteoporosis guidelines of the Dachverband Osteologie (DVO) [21]. The severity of OA was determined from preoperative radiographs using the Kellgren-Lawrence score [22]. To interpret the DXA data from the TKA patients in this study, we compared the results with 268 consecutive elderly patients scheduled for THA who had been analyzed in a previous study [10]. This retrospective study was approved by the local ethics committee
(2021-300036-WF) and was performed in accordance with the most recent version of the Declaration of Helsinki.

\section{Dual-energy X-ray absorptiometry (DXA)}

As part of routine clinical workup, we assessed bone mineral density (BMD) at the left and right proximal femur and lumbar spine (L1-L4) in all patients by dual-energy X-ray absorptiometry (DXA; Lunar Prodigy enCore 2007, GE Healthcare; Madison, WI, USA) according to the German osteoporosis guidelines (DVO). All measurements were performed within three months before TKA. $T$-scores expressing BMD standard deviations for young, sex-matched healthy adults were generated using the manufacturer's software. Based on the $T$-score, osteoporosis and osteopenia were diagnosed according to World Health Organization (WHO) guidelines (i.e., normal $T$-score $>-1.0$, osteopenia $T$-score $>-2.5 \leq-1.0$, osteoporosis $T$-score $\leq-2.5$ ).

\section{Statistical analysis}

GraphPad Prism ${ }^{\circledR}$ (version 9.0, GraphPad Software, La Jolla, CA) and SPSS $^{\circledR}$ statistical program (version 26.0, IBM, Armonk, New York, USA) were used for statistical analyses. Continuous variables are given as mean \pm standard deviation (SD) and categorical variables are expressed as number and percentage. The normality of the data distribution was tested by using the Shapiro-Wilk test. Unpaired data from two groups were tested for significance using Student's $t$ test for normally distributed data and Mann-Whitney $U$ test for non-normally distributed data. One-way ANOVA with Tukey's post hoc analysis was performed to analyze differences between more than two normally distributed groups multiple comparisons for data. Kruskal-Wallis test with Dunn's post hoc test for multiple comparisons was used for non-normally distributed data. Age- and weight-associated changes in $T$-scores were analyzed with linear regression analysis. The $p$ value, the coefficient of determination $R^{2}$ and the $95 \%$ confidence interval (CI) of the respective regression slopes were determined. To determine the independent influence of gender, age, BMI, or Kellgren-Lawrence score on the $T$-score, a multiple linear regression model was performed using the "enter" method to evaluate the influence of all variables simultaneously. Statistical significance was set to a 2-tailed $p$ value of 0.05 .

\section{Results}

We examined 109 consecutive patients (72 women and 37 men) with end-stage OA awaiting TKA (Fig. 1A, B). There was no difference between the sexes in terms of age (Fig. 1C) and BMI (Fig. 1D). Clinical risk factors for osteoporosis did 


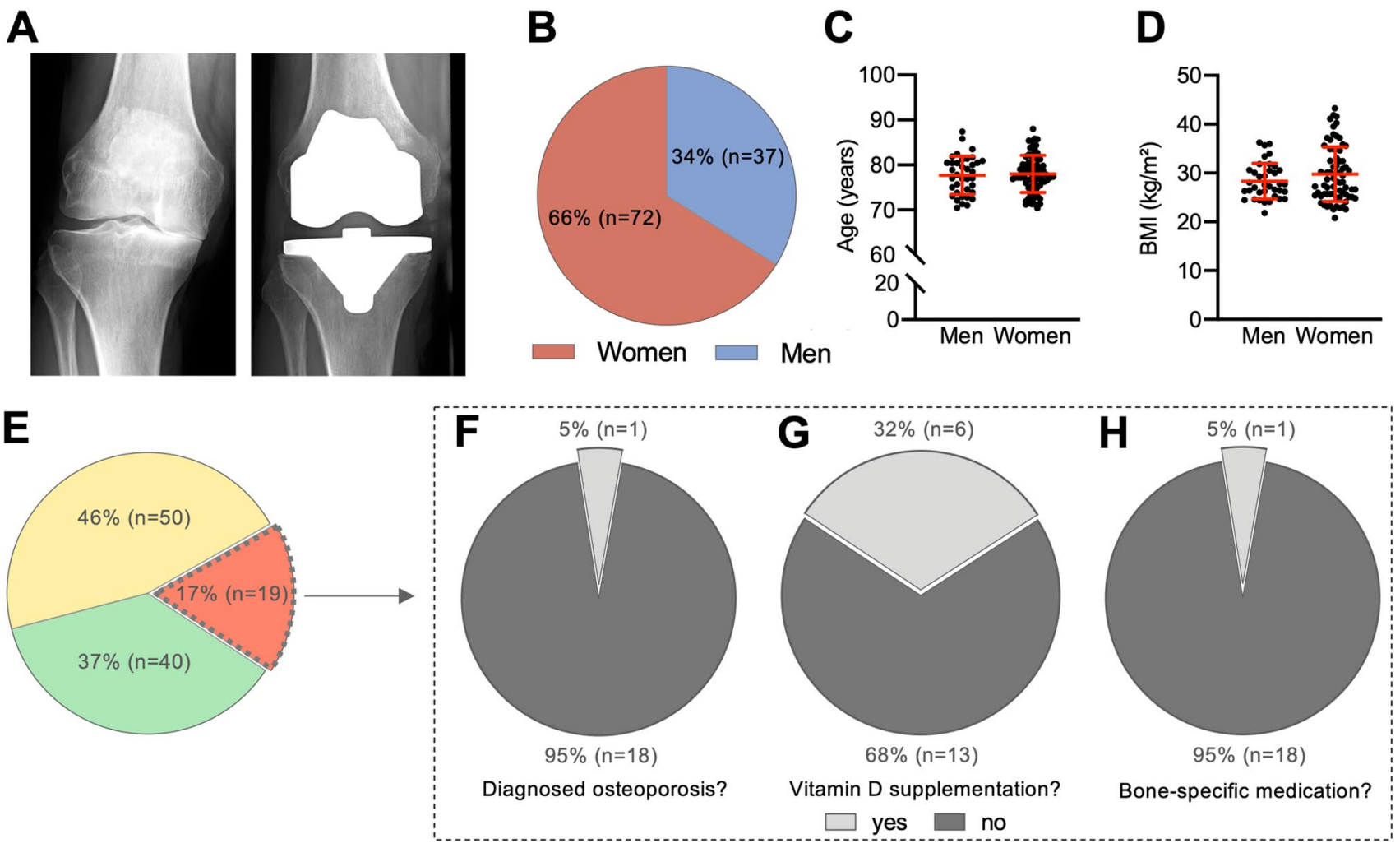

Fig. 1 Demographic characteristics and DXA results in patients scheduled for TKA. A Radiographs of a representative case of endstage medial osteoarthritis before (left panel) and after (right panel) TKA. B Sex distribution in the patient cohort. C Age and D BMI distribution between the sexes. E DXA results divided into the propor-

not differ between women and men (Table 1). Of the total patient cohort, $12 / 109$ patients $(11.0 \%)$ suffered at least one fracture in their history, with vertebral fractures in seven $(6.4 \%)$ and peripheral fractures in five patients (4.6\%). Eight patients $(7.3 \%)$ had a confirmed diagnosis of rheumatoid arthritis and 20 patients (18.3\%) of type 2 diabetes mellitus. In addition, eight patients $(7.3 \%)$ reported current or past use of oral glucocorticoids for more than three months, while seven patients $(6.4 \%)$ reported high-risk alcohol use, and twelve patients $(11.0 \%)$ were smokers. All demographic data as well as risk factors are summarized in Table 1, subdivided into women and men.

The analysis of DXA results showed that only 40 patients (36.7\%) awaiting TKA had normal $T$-scores, whereas the majority ( $n=69 ; 63.3 \%$ ) had reduced BMD (Fig. 1E). Specifically, osteopenia was detected in 50 (45.9\%) and osteoporosis in 19 patients $(17.4 \%)$. While osteoporosis had been previously diagnosed in only $1 / 19$ patients, it was first diagnosed in the remaining 18 patients (Fig. 1F), revealing a clinically relevant underdiagnosis in $95.0 \%$ of the cases. As a result, only six patients (31.6\%) received vitamin D supplementation (Fig. 1G). Furthermore, only tion of patients with osteoporosis (red), osteopenia (yellow), and normal BMD (green). F Evaluation of osteoporosis patients concerning the status of prior diagnosis establishment, $\mathbf{G}$ vitamin D substitution, and $\mathbf{H}$ specific antiresorptive treatment

the one patient $(5.3 \%)$ with previously diagnosed osteoporosis received a bone-specific medication (i.e., antiresorptive treatment) (Fig. 1H). When comparing the DXA results between women and men, the minimum $T$ - and the $Z$-score did not differ. However, as expected, the minimum absolute BMD value was significantly higher in men than in women (Table $1 ; p=0.003$ ).

Analyzing the different DXA measurement sites, the hip $T$-score was significantly lower in both the affected (i.e., scheduled for TKA) $(-0.8 \pm 1.2 ; p=0.009)$ and unaffected leg (i.e., contralateral side) $(-0.8 \pm 1.1 ; p=0.028)$ as compared to the lumbar spine $(-0.2 \pm 1.9$; Fig. $2 \mathrm{~A})$, while the $Z$-score differed significantly only between the hip in the affected leg $(0.3 \pm 1.1$ vs. $0.8 \pm 1.8 ; p=0.048)$ and lumbar spine (Fig. 2B). The BMD of the hips was also significantly lower in the affected $(0.9 \pm 0.2 ; p<0.0001)$ and unaffected leg $(0.9 \pm 0.1 ; p<0.0001)$ as compared to the lumbar spine $(1.2 \pm 0.2$; Fig. $2 \mathrm{C})$. No significant differences in BMD were evident in relation to the OA severity levels as measured by the Kellgren-Lawrence score (Fig. 2D-F).

Interestingly, there was no association between age and $T$-score at any measurement site in our study cohort 
Table 1 Demographic data, medical history, risk factors, and DXA results in male and female patients scheduled for TKA

\begin{tabular}{|c|c|c|c|}
\hline & $\begin{array}{l}\text { Women } \\
n=72\end{array}$ & $\begin{array}{l}\text { Men } \\
n=37\end{array}$ & $p$ \\
\hline \multicolumn{4}{|l|}{ Patient characteristics } \\
\hline Age (years) & $78.0 \pm 4.1$ & $77.7 \pm 4.3$ & 0.705 \\
\hline Height $(\mathrm{cm})$ & $163.6 \pm 7.1$ & $176.1 \pm 6.2$ & $<0.0001$ \\
\hline Weight (kg) & $79.3 \pm 14.0$ & $87.9 \pm 12.3$ & 0.002 \\
\hline BMI $\left(\mathrm{kg} / \mathrm{m}^{2}\right)$ & $29.8 \pm 5.6$ & $28.3 \pm 3.7$ & 0.163 \\
\hline Kellgren-Lawrence score & $3.5 \pm 0.6$ & $3.7 \pm 0.6$ & 0.064 \\
\hline \multicolumn{4}{|l|}{$\begin{array}{l}\text { Medical history and risk } \\
\text { factors }\end{array}$} \\
\hline Previous fragility fractures & $9 / 72(12.5 \%)$ & $3 / 37(8.1 \%)$ & $0.488^{\#}$ \\
\hline Vertebral fractures & $4 / 72(5.6 \%)$ & $3 / 37(8.1 \%)$ & $0.607^{\#}$ \\
\hline Peripheral fractures & $5 / 72(7.0 \%)$ & $0 / 37(0.0 \%)$ & N/A \\
\hline Rheumatoid arthritis & $7 / 72(9.7 \%)$ & $1 / 37(2.7 \%)$ & $0.183^{\#}$ \\
\hline Diabetes mellitus type 2 & $11 / 72(15.3 \%)$ & $9 / 37(24.3 \%)$ & $0.248^{\#}$ \\
\hline Glucocorticoids & $7 / 72(9.7 \%)$ & $1 / 37(2.7 \%)$ & $0.183^{\#}$ \\
\hline $\begin{array}{l}\text { Three or more units alco- } \\
\text { hol/day }\end{array}$ & $4 / 72(5.6 \%)$ & $3 / 37(8.1 \%)$ & $0.607^{\#}$ \\
\hline Current smoking & $6 / 72(8.3 \%)$ & $6 / 3716.2 \%)$ & $0.213^{\#}$ \\
\hline \multicolumn{4}{|l|}{ DXA results } \\
\hline$T$-Score $_{\text {Min }}$ & $-1.3 \pm 1.2$ & $-1.1 \pm 1.4$ & 0.406 \\
\hline Z-Score $_{\text {Min }}$ & $0.0 \pm 1.1$ & $-0.4 \pm 1.4$ & 0.911 \\
\hline $\mathrm{BMD}_{\mathrm{Min}}$ & $0.8 \pm 0.2$ & $1.0 \pm 0.2$ & 0.003 \\
\hline Osteoporosis & $13 / 72(18.1 \%)$ & $6 / 37(16.2 \%)$ & $0.810^{\#}$ \\
\hline Osteopenia & $37 / 72(51.4 \%)$ & $13 / 37(35.1 \%)$ & $0.107^{\#}$ \\
\hline Normal BMD & $22 / 72(30.6 \%)$ & $18 / 37(48.7 \%)$ & $0.063^{\#}$ \\
\hline
\end{tabular}

$n$ number of patients, $T$-score $_{\text {Min }}$ minimum $T$-score, $Z$-score Min $_{\text {mini- }}$ mum $Z$-score, $B M D_{M i n}$ minimum bone mineral density, $B M D$ bone mineral density

\#Determined by the $\chi^{2}$ test. The results are presented as mean \pm SD or $n(\%)$. Bold indicates significant differences $(p<0.05)$

(Fig. 3A-D). However, there was a positive linear association between BMI and $T$-scores in the affected (Fig. 3E) and unaffected leg (Fig. 3F). Although there was no association with lumbar spine measurements (Fig. 3G), minimum $T$-score also significantly increased with higher BMI (Fig. 3H).

Using a multiple linear regression model, we identified the Kellgren-Lawrence score, BMI, and glucocorticoid use as independent factors associated with the $T$-score (Table 2). Specifically, a higher Kellgren-Lawrence score was associated with a lower minimal $T$-score, while a lower BMI represented an independent influencing factor for a lower minimal $T$-score and a lower hip $T$-score of the affected side. The use of glucocorticoids was additionally associated with a lower $T$-score at the lumbar spine.

Finally, we compared the $T$-scores of patients scheduled for TKA with a previously published cohort of 268 THA patients (178 women and 90 men) [10]. The two cohorts were similar in age (TKA: $77.9 \pm 4.1$ years vs. THA: $78.2 \pm 4.8$ years; $p=0.48$ ), but the TKA patients presented with significantly higher BMI values (TKA: $29.3 \pm 5.0 \mathrm{~kg} /$ $\mathrm{m}^{2}$ vs. THA: $\left.27.5 \pm 4.1 \mathrm{~kg} / \mathrm{m}^{2} ; p=0.0003\right)$. There were no significant differences between the two groups in the hip $T$-scores of the affected (Fig. 4A) or unaffected leg (Fig. 4B), lumbar spine (Fig. 4C), or the minimum $T$-score (Fig. 4D), suggesting that knee and hip OA likely do not affect osteoporosis differently.

\section{Discussion}

In the present study, we aimed to investigate the prevalence of reduced BMD, including potential influencing factors, in consecutive elderly knee OA patients prior to TKA. This study is the first to address this question in a European patient population without preselection of patients with certain risk factors (i.e., unbiased approach). Special focus was also given to the extent to which patients diagnosed with osteoporosis receive adequate treatment.

We demonstrated that a substantial proportion of knee OA patients had osteopenia and osteoporosis in terms of BMD $T$-scores $\leq-1.0$ and $\leq-2.5$, respectively. Through our approach, most were first diagnosed with previously unknown and untreated osteoporosis, indicating a clinically relevant underdiagnosis and treatment gap. Further investigation revealed that especially patients with a low BMI, oral glucocorticoid use, and high Kellgren-Lawrence score were at particular risk for reduced BMD. DXA results did not show differences between the hips of the affected and the unaffected side. Therefore, pain-related unloading of the affected leg seems not to lead to a side-specific difference in BMD of the unilateral hip. Only BMD values in the lumbar spine were significantly higher compared with the hips, probably due to accompanying degenerative changes in the spine [23, 24].

Interestingly, no differences in BMD were observed between elderly patients awaiting TKA and those scheduled for THA. While in our previous study [10], analyzing patients prior to THA, osteoporosis was diagnosed in $18 \%$ and osteopenia in $41 \%$, in the present study osteoporosis was diagnosed in $17 \%$ and osteopenia in $46 \%$. Also, no significant differences were measured at the individual DXA measurement sites between these two patient cohorts, indicating that the manifestation site of $\mathrm{OA}$ is independent of BMD or, in other words, that knee and hip OA equally affect BMD.

There seem to be substantial geographic differences in the occurrence of osteoporosis. In this regard, Asian studies in particular show high osteoporosis rates by DXA in patients undergoing TKA, but the underlying reason is unclear. Specifically, osteoporosis was detected in 59.8\% of Chinese postmenopausal women $(69.7 \pm 8.5$ years $)$ prior 

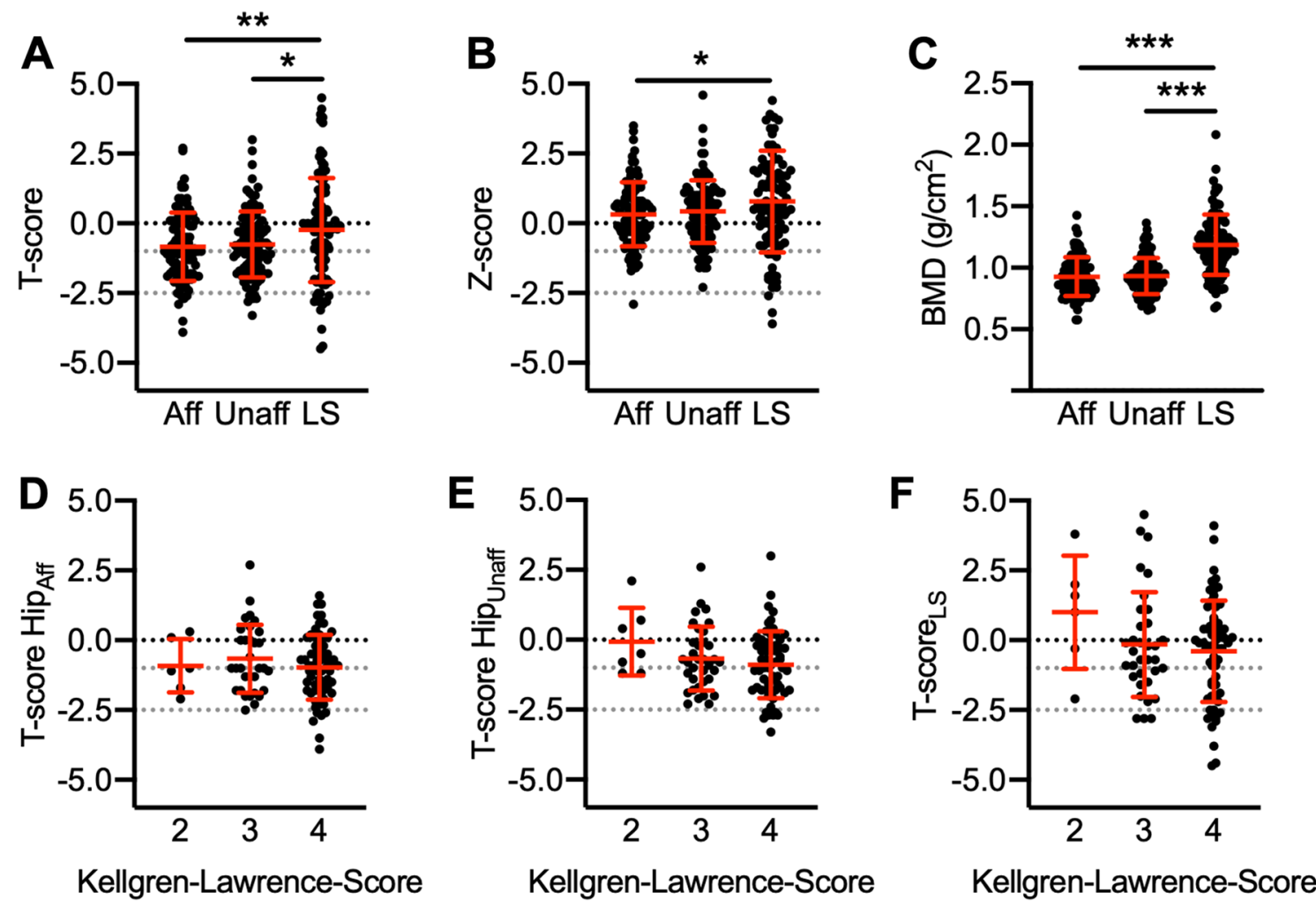

Fig. 2 Comparison of DXA results between different measurement sites and radiological OA-grades. A DXA $T$-scores of both hips (affected and unaffected leg) and the lumbar spine, B Z-scores, and $\mathbf{C}$ BMD. D Comparison of the hip $T$-scores of the affected leg, $\mathbf{E}$ unaffected leg, $\mathbf{F}$ and lumbar spine between individual Kellgren-Law-

to TKA [19]. The prevalence is markedly lower in our cohort $(18.1 \%)$ even though our patients are comparably older $(77.9 \pm 4.1$ years). An analysis performed in Korea also showed a substantially higher prevalence of osteoporosis $(50.0 \%$ of the total cohort) [17]. A comparison with the prevalence from other studies appears inaccurate, as a solely postoperative assessment of BMD or the lack of distinction between THA and TKA had been considered as confounding factors $[8,9,18,25-27]$. The data of the present study, which appear to reflect plausible results considering previous studies analyzing prevalence of osteoporosis in the general population [28,29], represent the first representative and consecutive data analysis on osteoporosis rates in elderly patients awaiting TKA in a Central European country.

Despite the lower prevalence as compared to Asian countries, the clinically relevant underdiagnosis of osteoporosis presents a serious issue, which is inevitably linked to a treatment gap and strengthens the need for routinely performed DXA measurements before TKA. This is an important necessity since patients with osteoporosis present an increased risk of atraumatic or low-energy fractures anyway $[30,31]$, but also exhibit a special additional risk profile rence scores of the operated knee. Ordinary one-way ANOVA and Tukey's multiple comparison test was used in all panels. Aff affected leg, Unaff unaffected leg, $L S$ lumbar spine, $T$-score Hip Aff $_{\text {Hip } T \text {-score }}$

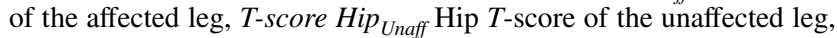
$T$-score $_{L S}$ lumbar spine $T$-score. ${ }^{*} p<0.05, * * p<0.01, * * * p<0.0001$

in the context of TKA, namely intraoperative and periprosthetic fractures, component migration, aseptic loosening [12-16, 32, 33].

Especially, considering the increasing trend of the prevalence of osteoporosis [34], the importance for standardized implementation of DXA measurements prior to TKA in elderly patients will increase in the future. Failure of treatment in osteoporotic patients is also an important concern, as appropriate specific osteoporosis therapy can lead to a significantly improved outcome [32, 33, 35-38]. In this way, antiresorptive and osteoanabolic drugs, like bisphosphonates, denosumab or teriparatide, can significantly prevent periprosthetic bone loss after TKA in the tibia and femur, thus effectively reducing the risk of periprosthetic fractures [32, 33, 35, 36, 39]. Periprosthetic bone loss, which can occur regularly and already in the first months after surgery [40, 41], may be a particular relevant problem in osteoporotic patients in terms of skeletal-related complications, and this bone loss can be effectively counteracted by specific osteoporosis therapy, especially in the metaphyseal region [38]. As a result, antiresorptive treatment in patients suffering from osteoporosis after total joint arthroplasty of the lower 


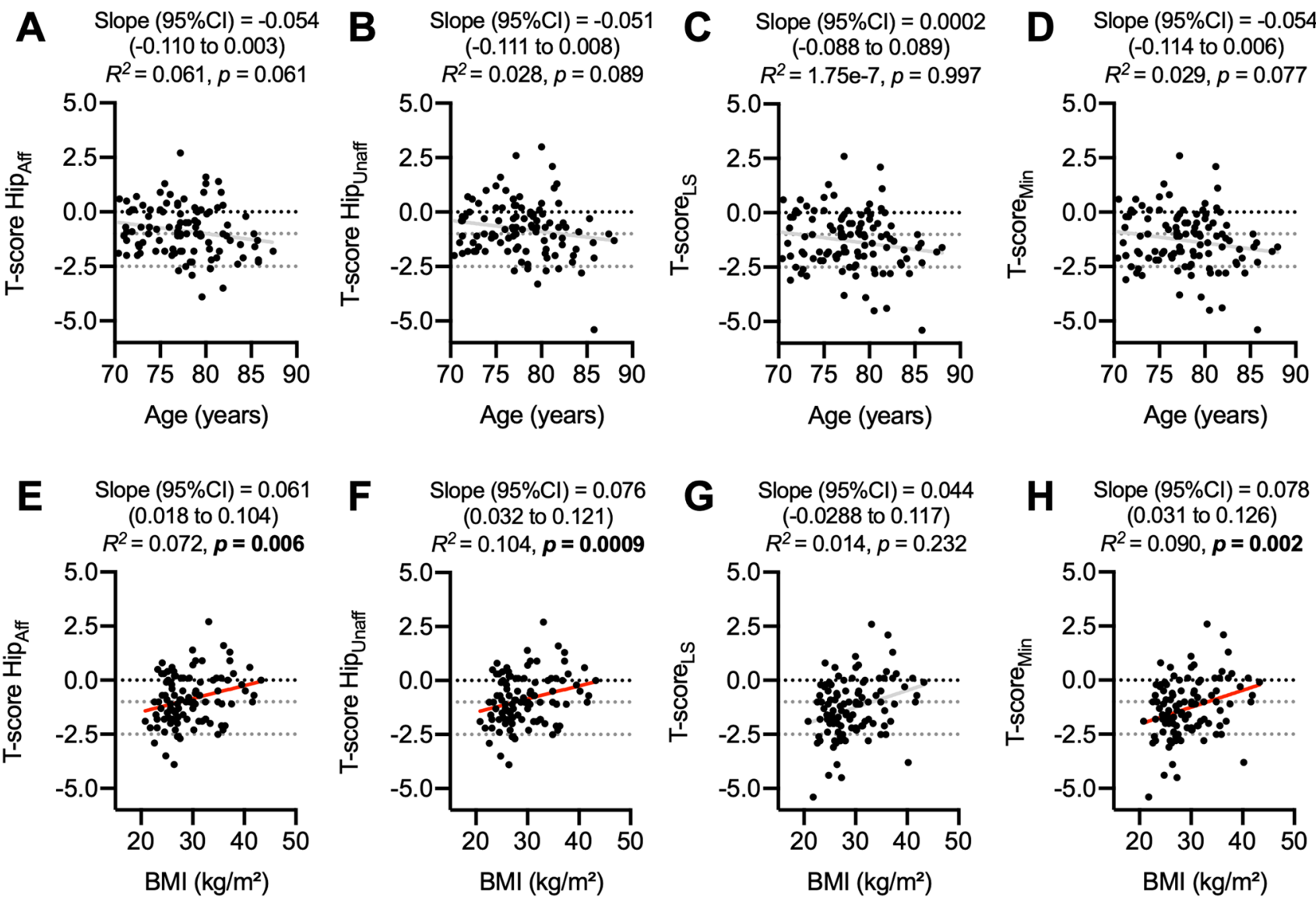

Fig. 3 Associations between age or BMI and DXA $T$-score. A Linear regression analysis of hip $T$-scores of the affected leg, $\mathbf{B}$ unaffected leg, $\mathbf{C}$ lumbar spine, $\mathbf{D}$ and minimum $T$-score as a function of age $(\mathbf{E}-\mathbf{H}$, respective) as well as BMI, respectively. Linear regression

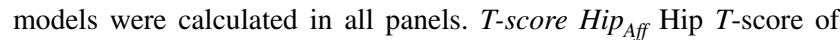

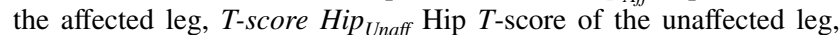
$T$-score $_{L S}$ lumbar spine $T$-score, $T$-score Min $_{\text {in }}$ minimum $T$-score, $B M I$ body mass index
Table 2 Multiple linear regression model analyzing the independent factors associated with BMD $T$-scores

\begin{tabular}{|c|c|c|c|c|c|c|c|c|c|}
\hline & \multicolumn{3}{|c|}{$T$-Score $_{\text {Min }}$} & \multicolumn{3}{|c|}{$T$-Score Hip $_{\text {Aff }}$} & \multicolumn{3}{|l|}{$T$-Score $_{\mathrm{LS}}$} \\
\hline & $\beta$ & $T$ & $p$ & $\beta$ & $T$ & $p$ & $\beta$ & $T$ & $p$ \\
\hline (Intercept) & & 0.753 & 0.453 & & 0.587 & 0.558 & & -0.049 & 0.961 \\
\hline Age & -0.124 & -1.411 & 0.161 & -0.143 & -1.529 & 0.130 & 0.030 & 0.302 & 0.763 \\
\hline KLS & -0.247 & -2.779 & 0.006 & -0.079 & -0.826 & 0.411 & -0.161 & -1.632 & 0.106 \\
\hline Sex & -0.100 & -1.102 & 0.273 & -0.020 & -0.205 & 0.838 & -0.159 & -1.590 & 0.115 \\
\hline BMI & 0.263 & 2.955 & 0.004 & 0.233 & 2.464 & 0.016 & 0.112 & 1.127 & 0.262 \\
\hline Corticosteroids & -0.227 & -2.569 & 0.012 & -0.276 & -2.938 & 0.004 & -0.214 & -2.188 & 0.031 \\
\hline$R^{2}$ adjusted & \multicolumn{3}{|c|}{$0.190^{* *}$} & \multicolumn{3}{|c|}{$0.140 * *$} & \multicolumn{3}{|c|}{$0.067 * *$} \\
\hline
\end{tabular}

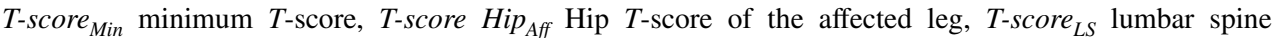
$T$-score, $K L S$ Kellgren-Lawrence score, $B M I$ body mass index

Bold indicates significant independent predictors $(p<0.05)$. ** $p<0.001$ for the multiple linear regression model. Regression coefficients were estimated for sex $(0=$ male, $1=$ female $)$ and glucocorticoid use as a bivariate variable $\left(0=\right.$ no, $1=$ yes). Age and BMI were given in years (year) and $\mathrm{kg} / \mathrm{m}^{2}$, respectively extremity is associated with a significantly lower revision rate and an almost twofold increase in implant survival [37]. Considering the high prevalence of osteoporosis in elderly patients with potential implications for treatment, the recommendation to routinely perform DXA 

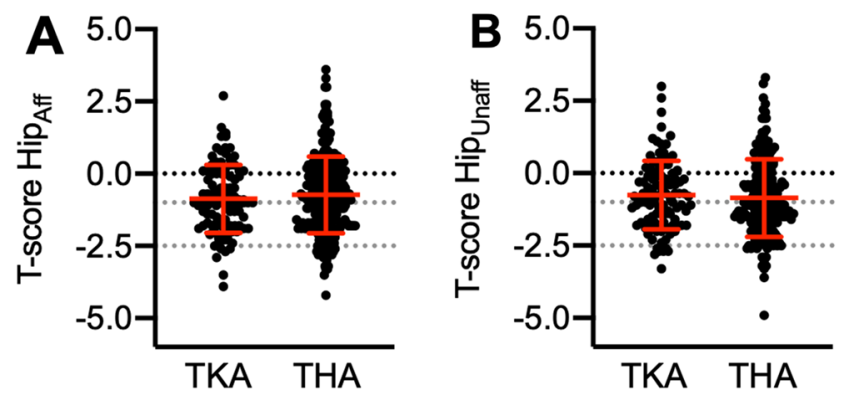

Fig. 4 Differences between $T$-scores in elderly TKA vs. THA patients. Different measurement sites are displayed. Comparison of hip $T$-scores of $\mathbf{A}$ the affected leg, $\mathbf{B}$ unaffected leg, $\mathbf{C}$ lumbar spine, $\mathbf{D}$ and minimum $T$-score. $t$ test was used in all panels. T-score Hip Aff

examination in patients $\geq 70$ years of age is strongly highlighted to avoid complications and to ensure long implant survival.

\section{Conclusion}

In elderly patients $\geq 70$ years in Central Europe with endstage OA scheduled for TKA, a substantial proportion was diagnosed with reduced BMD. Most osteoporosis patients did not receive adequate treatment, indicating clinically relevant underdiagnosis and undertreatment. Low BMI, high OA severity, and the use of glucocorticoids were identified as independent factors associated with poor BMD. No differences in BMD were found when comparing patients before TKA and THA. Considering the impact on outcome, general DXA screening for elderly patients $\geq 70$ years of age should be recommended before TKA. Population differences need to be respected concerning the prevalence of osteoporosis in orthopedic cohorts.

Funding Open Access funding enabled and organized by Projekt DEAL. This study was not funded by any individual or organization.

\section{Declarations}

Conflict of interest The authors declare that they have no conflict of interest.

Ethical approval This retrospective study was approved by the local ethics committee (2021-300036-WF).

Informed consent Informed consent was obtained from all individual participants included in the study.

Open Access This article is licensed under a Creative Commons Attribution 4.0 International License, which permits use, sharing, adaptation, distribution and reproduction in any medium or format, as long
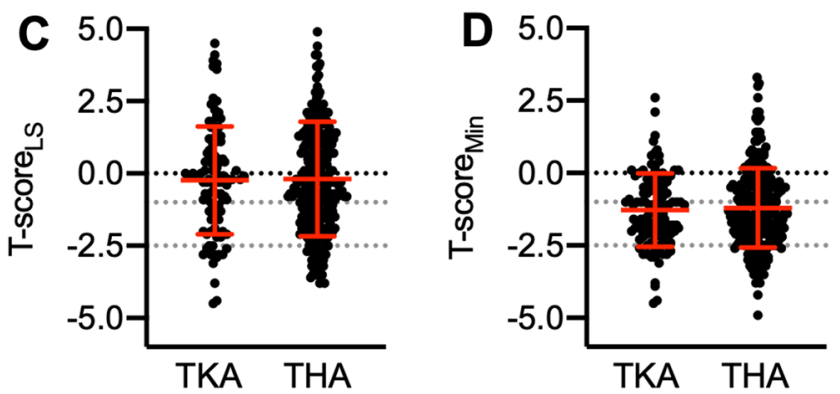

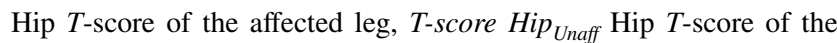
unaffected leg, $T$-score ${ }_{L S}$ lumbar spine $T$-score, $T$-score Min $_{\text {- }}$ minimum $T$-score

as you give appropriate credit to the original author(s) and the source, provide a link to the Creative Commons licence, and indicate if changes were made. The images or other third party material in this article are included in the article's Creative Commons licence, unless indicated otherwise in a credit line to the material. If material is not included in the article's Creative Commons licence and your intended use is not permitted by statutory regulation or exceeds the permitted use, you will need to obtain permission directly from the copyright holder. To view a copy of this licence, visit http://creativecommons.org/licenses/by/4.0/.

\section{References}

1. Steinhaus ME, Christ AB, Cross MB (2017) Total knee arthroplasty for knee osteoarthritis: support for a foregone conclusion? HSS J 13:207-210

2. Fucentese SF, Koch PP (2021) A novel augmented realitybased surgical guidance system for total knee arthroplasty. Arch Orthop Trauma Surg 141:2227-2233

3. Alpaugh K, Ast MP, Haas SB (2021) Immersive technologies for total knee arthroplasty surgical education. Arch Orthop Trauma Surg 141:2331-2335

4. Meyer M, Renkawitz T, Vollner F, Benditz A, Grifka J, Weber M (2021) Pros and cons of navigated versus conventional total knee arthroplasty-a retrospective analysis of over 2400 patients. Arch Orthop Trauma Surg 141:1983-1991

5. Wallace IJ, Worthington S, Felson DT, Jurmain RD, Wren KT, Maijanen H, Woods RJ, Lieberman DE (2017) Knee osteoarthritis has doubled in prevalence since the mid-20th century. Proc Natl Acad Sci USA 114:9332-9336

6. Nguyen US, Zhang Y, Zhu Y, Niu J, Zhang B, Felson DT (2011) Increasing prevalence of knee pain and symptomatic knee osteoarthritis: survey and cohort data. Ann Intern Med 155:725-732

7. Berenbaum F, Wallace IJ, Lieberman DE, Felson DT (2018) Modern-day environmental factors in the pathogenesis of osteoarthritis. Nat Rev Rheumatol 14:674-681

8. Lingard EA, Mitchell SY, Francis RM, Rawlings D, Peaston R, Birrell FN, McCaskie AW (2010) The prevalence of osteoporosis in patients with severe hip and knee osteoarthritis awaiting joint arthroplasty. Age Ageing 39:234-239

9. Bernatz JT, Brooks AE, Squire MW, Illgen RI 2nd, Binkley NC, Anderson PA (2019) Osteoporosis is common and undertreated prior to total joint arthroplasty. J Arthroplast 34:1347-1353 
10. Delsmann MM, Strahl A, Muhlenfeld M, Jandl NM, Beil FT, Ries C, Rolvien T (2021) High prevalence and undertreatment of osteoporosis in elderly patients undergoing total hip arthroplasty. Osteoporos Int 32:1661-1668

11. Anderson PA, Morgan SL, Krueger D, Zapalowski C, Tanner B, Jeray KJ, Krohn KD, Lane JP, Yeap SS, Shuhart CR, Shepherd J (2019) Use of bone health evaluation in orthopedic surgery: 2019 ISCD official position. J Clin Densitom 22:517-543

12. Frenzel S, Vecsei V, Negrin L (2015) Periprosthetic femoral fractures-incidence, classification problems and the proposal of a modified classification scheme. Int Orthop 39:1909-1920

13. Peerakul Y, Leeyaphan J, Rojjananukulpong K (2021) The association between bone mineral density and postoperative drainage volume following cruciate-substituting primary total knee arthroplasty: a cross-sectional study. Knee Surg Relat Res 33:22

14. Hampton CB, Berliner ZP, Nguyen JT, Mendez L, Smith SS, Joseph AD, Padgett DE, Rodriguez JA (2020) Aseptic loosening at the tibia in total knee arthroplasty: a function of cement mantle quality? J Arthroplast 35:S190-S196

15. Purudappa PP, Ramanan SP, Tripathy SK, Varatharaj S, Mounasamy V, Sambandam SN (2020) Intra-operative fractures in primary total knee arthroplasty—a systematic review. Knee Surg Relat Res 32:40

16. Andersen MR, Winther NS, Lind T, Schroder HM, Flivik G, Petersen MM (2017) Low preoperative BMD is related to high migration of tibia components in uncemented TKA-92 patients in a combined DEXA and RSA study with 2-year follow-up. J Arthroplast 32:2141-2146

17. Ha CW, Park YB (2020) Underestimation and undertreatment of osteoporosis in patients awaiting primary total knee arthroplasty. Arch Orthop Trauma Surg 140:1109-1114

18. Bernatz JT, Krueger DC, Squire MW, Illgen RL 2nd, Binkley NC, Anderson PA (2019) Unrecognized osteoporosis is common in patients with a well-functioning total knee arthroplasty. J Arthroplast 34:2347-2350

19. Tao Y, Tang S, Huang X, Wang H, Zhou A, Zhang J (2021) Prevalence and risk factors of osteoporosis in Chinese postmenopausal women awaiting total knee arthroplasty. Clin Interv Aging 16:379-387

20. Muhlenfeld M, Strahl A, Bechler U, Jandl NM, Hubert J, Rolvien $\mathrm{T}$ (2021) Bone mineral density assessment by DXA in rheumatic patients with end-stage osteoarthritis undergoing total joint arthroplasty. BMC Musculoskelet Disord 22:173

21. Thomasius F, Baum E, Bernecker P, Böcker W, Brabant T, Clarenz P, Demary W, Dimai HP, Engelbrecht M, Engelke K, Fratermann U, Grieser T, Gulich M, Hadji P, Henning J, Jehle PM, Kern PM, Ketteler M, Klatt G, Kraenzlin M, Maus U, Meier C, Moser U, Müller D, Peichl P, Pfeifer M, Rintelen B, Rueger JM, Schober H-C, Schöffel D, Schwarz H, Siggelkow H, Suhm N, Wiese KG, Wörtler K, Kurth AA (2018) DVO Leitlinie 2017 zur Prophylaxe, Diagnostik und Therapie der Osteoporose bei postmenopausalen Frauen und Männern: Kurzversion. Osteologie 27:154-160

22. Kellgren JH, Lawrence JS (1957) Radiological assessment of osteo-arthrosis. Ann Rheum Dis 16:494-502

23. Azami A, Anari H, Iranparvar M, Azizi A, Habibzadeh A (2019) Comparison of bone mineral densitometry at 2 sites versus 3 sites in patients suspicious for osteoporosis. Clin Med Insights Arthritis Musculoskelet Disord 12:1179544119849017

24. Tenne M, McGuigan F, Besjakov J, Gerdhem P, Akesson K (2013) Degenerative changes at the lumbar spine-implications for bone mineral density measurement in elderly women. Osteoporos Int 24:1419-1428

25. Gundry M, Hopkins S, Knapp K (2017) A review on bone mineral density loss in total knee replacements leading to increased fracture risk. Clin Rev Bone Miner Metab 15:162-174
26. Prince JM, Bernatz JT, Binkley N, Abdel MP, Anderson PA (2019) Changes in femoral bone mineral density after total knee arthroplasty: a systematic review and meta-analysis. Arch Osteoporos 14:23

27. Jaroma A, Soininvaara T, Kroger H (2016) Periprosthetic tibial bone mineral density changes after total knee arthroplasty. Acta Orthop 87:268-273

28. Kanis JA, Cooper C, Rizzoli R, Reginster JY, Scientific Advisory Board of the European Society for Clinical and Economic Aspects of osteoporosis and the Committees of Scientific Advisors and National Societies of the International Osteoporosis Foundation (2019) European guidance for the diagnosis and management of osteoporosis in postmenopausal women. Osteoporos Int 30:3-44

29. Hernlund E, Svedbom A, Ivergard M, Compston J, Cooper C, Stenmark J, McCloskey EV, Jonsson B, Kanis JA (2013) Osteoporosis in the European Union: medical management, epidemiology and economic burden. A report prepared in collaboration with the International Osteoporosis Foundation (IOF) and the European Federation of Pharmaceutical Industry Associations (EFPIA). Arch Osteoporos 8:136

30. Woltman K, den Hoed PT (2010) Osteoporosis in patients with a low-energy fracture: 3 years of screening in an osteoporosis outpatient clinic. J Trauma 69:169-173

31. Augat P, Weyand D, Panzer S, Klier T (2010) Osteoporosis prevalence and fracture characteristics in elderly female patients with fractures. Arch Orthop Trauma Surg 130:1405-1410

32. Jaroma AV, Soininvaara TA, Kroger H (2015) Effect of one-year post-operative alendronate treatment on periprosthetic bone after total knee arthroplasty. A seven-year randomised controlled trial of 26 patients. Bone Jt J 97-B:337-345

33. Russell LA (2013) Osteoporosis and orthopedic surgery: effect of bone health on total joint arthroplasty outcome. Curr Rheumatol Rep 15:371

34. Reginster JY, Burlet N (2006) Osteoporosis: a still increasing prevalence. Bone 38:S4-9

35. Ledin H, Good L, Aspenberg P (2017) Denosumab reduces early migration in total knee replacement. Acta Orthop 88:255-258

36. Murahashi Y, Teramoto A, Jimbo S, Okada Y, Kamiya T, Imamura R, Takashima H, Watanabe K, Nagoya S, Yamashita T (2020) Denosumab prevents periprosthetic bone mineral density loss in the tibial metaphysis in total knee arthroplasty. Knee 27:580-586

37. Prieto-Alhambra D, Javaid MK, Judge A, Murray D, Carr A, Cooper C, Arden NK (2011) Association between bisphosphonate use and implant survival after primary total arthroplasty of the knee or hip: population based retrospective cohort study. BMJ 343:d7222

38. Shi M, Chen L, Wu H, Wang Y, Wang W, Zhang Y, Yan S (2018) Effect of bisphosphonates on periprosthetic bone loss after total knee arthroplasty: a meta-analysis of randomized controlled trials. BMC Musculoskelet Disord 19:177

39. Suzuki T, Sukezaki F, Shibuki T, Toyoshima Y, Nagai T, Inagaki K (2018) Teriparatide administration increases periprosthetic bone mineral density after total knee arthroplasty: a prospective study. J Arthroplast 33:79-85

40. Karbowski A, Schwitalle M, Eckardt A, Heine J (1999) Periprosthetic bone remodelling after total knee arthroplasty: early assessment by dual energy X-ray absorptiometry. Arch Orthop Trauma Surg 119:324-326

41. Windisch C, Windisch B, Kolb W, Kolb K, Grutzner P, Roth A (2012) Osteodensitometry measurements of periprosthetic bone using dual energy X-ray absorptiometry following total knee arthroplasty. Arch Orthop Trauma Surg 132:1595-1601

Publisher's Note Springer Nature remains neutral with regard to jurisdictional claims in published maps and institutional affiliations. 